\title{
Por uma Investigação em Artes Cênicas: um caminho cartográfico possível
}

For an investigation in performing arts: a
possible path way through cartography

Otavio Miguel Chaves de Sousa ${ }^{1}$

Renato Ferracini ${ }^{2}$ 


\section{Resumo}

Assumindo a complexidade e as possibilidades da pesquisa acadêmica no campo das artes, este artigo aborda e discute alguns aspectos da investigação em artes que tem como escopo o fazer do artista em processo de criação, buscando identificar e refletir sobre parâmetros metodológicos específicos de uma investigação em Artes Cênicas. Identificando um caráter cartográfico implícito, é articulada ainda uma apropriação do conceito de cartografia que é trazido por Gilles Deleuze e Felix Guattari, para aprofundar as reflexões acerca das particularidades da metodologia em questão e propor um material de conhecimento acadêmico que seja condizente com seus aspectos processuais.

Palavras-chave: Cartografia; prática de criação; escrita; metodologia de investigação

\section{Abstract}

Considering the complexity and the possibilities about academic research in the realm of arts, this article discusses some aspects related to an investigation in arts that has in its scope the doing of the artist in a creative process, aiming to identify and reflect about the specific methodological parameters in an investigation in Performing Arts. Identifying an implicit cartographic path, it is articulated an appropriation of the concept of cartography brought by Gilles Deleuze and Felix Guattari, to verticalize the reflections about the particularities of the methodology here discussed and suggest a subject of academic knowledge that is appropriate to the aspects of the creative process.

Keywords: Cartography; practice of creation; writing; research methodology

E-ISSN: 2358.6958

Doutorando da Universidade de Lisboa. Artista cênico e visual. otaviodsousa@hotmail.com

2 Prof. Dr. Instituto de Artes no Programa de Pós-Graduação em Artes da Cena - UNICAMP. Ator-pesquisador do Lume. renato@lumeteatro.com.br 
Desde o século passado o conhecimento científico começou a abrir espaço para um repensar epistemológico de paradigmas que, desde o século $\mathrm{XVI}$, foram se estruturando como quantificadores: "o que não é quantificável é cientificamente irrelevante"(Santos, 2008, p. 28). Este paradigma moderno, advindo das ciências naturais e tendo como lugar central as ideias matemáticas, assentava o conhecimento científico sobre os processos de classificação e sistematização, onde "conhecer significa dividir e classificar para depois poder determinar relações sistemáticas entre o que se separou" (Santos, 2008, p. 28). Ou seja, todo o conhecimento era centrado em investigações ligadas estritamente ao racionalismo e à simplificação.

Embora ainda no final do século passado a ciência mantivesse a primazia de uma visão racionalista e de enquadramentos ligados ao paradigma moderno, como traz Silvio Zamboni (2001), o repensar epistemológico que começou a emergir passou a colocar em pauta um conhecimento que deu abertura a todo um conjunto de novos pressupostos, para além dos teóricos e empíricos que eram dominantes no paradigma moderno e que buscavam a aplicabilidade ou comprovação de teorias e leis. "É um conhecimento sobre as condições de possibilidade. As condições de possiblidade da acção humana projetada no mundo a partir de um espaço-tempo local" (Santos, 2008, p. 77). Significa dizer que o conhecimento científico pós-moderno se abre para a experiência do próprio fazer científico. E, na medida em que esse conhecimento reflete sobre possibilidades do fazer investigação, não se instaura como um caminho para explorar ou determinar leis e circunstancias fixas, mas sim, como um investigar também parâmetros metodológicos. Até porque, se trata de conhecimento que em certa medida não possui método, pois se estabelece em uma pluralidade metodológica (Santos, 2008).

O paradigma moderno foi um modelo científico de conhecimento que se fez necessário para sua época, e que depois se mostrou insatisfatório pelo próprio conhecimento que permitiu construir. A problemática é que tal período deixou uma tradição. Tradição essa que Margarida Vine $(2005$, p. 7) aborda como um legado cartesiano do "penso, logo existo", que seria uma herança do pensamento cartesiano e principalmente do racionalismo. No contexto dessa tradição, há igualmente a tendência a homogeneizar as investigações e suas metodologias dentro das instituições acadêmicas, incluindo também as que são desenvolvidas nas áreas artísticas. Assim sendo, torna-se uma necessidade refletir acerca de metodologias de investigação próprias da área artística.

Embora as investigações nas áreas artísticas ganhem cada vez mais autonomia na definição de seus sistemas de investigação dentro da acadêmica, o que acontece em muitos casos é a tentativa de padronizar e enquadrar as artes dentro de parâmetros científicos e de metodologias que advém de outras áreas. Uma destas metodologias, por exemplo, é a pesquisa qualitativa que advém das áreas sociais. Isso se dá, segundo Hélio Brantes (2013, p. 603), em virtude do caráter conceitual da investigação em artes e de algumas proximidades de parâmetros metodológicos mais flexíveis e sensíveis. Entretanto, como afirma Helena Ferreira (2015, p. 112), "a investigação em artes evidencia, pois, um conjunto de métodos, a saber, transdisciplinares, heterogéneos, reflexivos, variáveis, contingentes, medium-específicos, que não se enquadram em modelos unidimensionais provenientes de outras áreas". 
A arte enquanto disciplina académica produz conhecimento sistemático e, mesmo que o faça sobre pressupostos particulares, podemos acolhê-la em um conceito estendido de ciência, que é trazido por Sven Hansson (2008), como investigação sistemática e crítica que procura conhecimento acerca do Homem e do que o rodeia. A questão é que este conhecimento que é sistematizado se encontra fundamentado sobre propósitos outros, que não os de comprovação de verdades cientificas ou a instauração de modelos a serem reproduzidos, como afirmam os atores e pesquisadores Moacir Romanini Junior e Matteo Bonfitto:

[...] ao contrário da ciência [tradicional], não nos referimos a comprovação da verdade, mas sim, da instauração de uma verdade, que nasce da especificidade de parâmetros metodológicos em constante construção, e que embora realizada sobre padrões científicos, terá sempre uma arquitetura particular, distante das uniformidades (2016, p. 117).

Na verdade, essas peculiaridades de uma "arquitetura particular", que vão sendo construídas no fazer da investigação, é que fazem da área artística um terreno fértil de investigação. $O$ fato de se referir a uma metodologia aberta, que vai sendo produzida à medida que o próprio trabalho artístico vai sendo construído, estabelece uma metodologia constitutiva que, ao assim ser, trabalha com critérios de conhecimento e com produção de um conhecimento que se faz de um modo particular em cada processo, onde instaura sempre novo conhecimento acerca do fazer investigativo e do fazer artístico, bem como das reflexões sobre arte. Como afirma Henk Slager (2015, p. 63), "essa forma de investigação não pode ser canalizada através de rígidas orientações académico-científicas que tratam da generalização, duplicação e quantificação, pois envolve-se no único, no qualitativo, no particular, no local".

Tendo em vista estas considerações e buscando refletir sobre as discussões já consolidadas de investigação em artes - geralmente com ênfase nas Artes Visuais -, o que se pretende aqui é elucidar os parâmetros metodológicos específicos de uma investigação em Artes Cênicas, que traga como objetivo e objeto o fazer do artista em processo de criação, refletindo sobre eles e identificando um caráter cartográfico implícito. Neste intuito, são apresentadas primeiramente considerações do que seria uma tipologia base de investigação em artes; em seguida, articulam-se as características próprias de uma investigação em Artes Cênicas em contraponto com as Artes Visuais; para em um terceiro momento, abordar o método cartográfico como possibilidade de pensar essa metodologia de investigação e propor um material teórico que seja condizente com seus aspectos e seu objeto igualmente processuais.

\section{Uma tipologia base de investigação em artes}

Distinta das investigações nas demais áreas da ciência e também da pesquisa sobre arte, cuja qual, segundo Sandra Rey (1996), diz respeito ao estudo histórico, teórico e crítico, relacionando-se com a obra enquanto produto final, a investigação em artes ou investigação artística, como também é chamada, envolve parâmetros metodológicos específicos e se configura como a investigação do artista sobre sua 
prática de instauração da obra - seu processo de criação. Cabe dizer que a pesquisa (ou investigação) sobre arte estaria mais relacionada à abordagem de um objeto de estudo que se encontra inserido no meio artístico, sobre o qual se constrói um estudo. Enquanto que, por sua vez, a investigação em artes instaura seu próprio objeto a ser explorado, e ela mesma é meio de construção artística produzindo material artístico em arte, ao contrário de apenas material linguístico através dela.

Esta Investigação tem como ponto de partida a criação do artista. Encontrando apoio teórico na poética que segundo René Passeron (2004, p. 10), "é o pensamento possível da criação", simultaneamente, científico e filosófico, que tem seu interesse nas condutas que constroem a obra e que " se instaura como consciência de toda a instauração". A investigação em artes "[...] não se caracteriza nem como o estudo da obra feita nem da obra a fazer, como projeto" (Rey, 1996, p. 83-84), mas, como o processo que se faz. Deste modo, esse viés de trabalho refuga a existência de projetos previamente estabelecidos de maneira rígida, tendo em vista que o processo possui um desenrolar complexo e auto estrutural. Trata-se de um metodologia de investigação que se caracteriza como o devir, do qual falam Deleuze e Guattari (1997), que não se dá por filiação ou dependência, mas por um progredir comunicativo ou contagioso. O devir seria um transformar-se da investigação que não tem um ponto de partida e nem um ponto ao qual necessita chegar, ela está "[...] centrada no fazer e no devir da criação artística do seu autor" (Mendes, 2015, p. 70), é um investigar que se constrói no próprio caminho que vai trilhando.

O que será estudado, portanto, não está pré-definido por materiais teóricos ou modelos de investigações já constituídos. Embora a abordagem e o estudo de material teórico estejam inseridos na investigação do artista em seu processo de composição, esta não estabelece a teoria como condição prévia ou como fundamento, ao contrário: os encontros com a teoria vão se dando em caminho de investigação. "São as interpelações da práxis que direcionarão a pesquisa teórica"(Rey, 1996, p. 90).

A metodologia de investigação em arte não tem como proposta ser uma a-metodologia, mas acaba adquirindo essa qualidade ao endossar o processo de criação do artista como investigação acadêmica e assumir que esses processos artísticos possuem características particulares e uma complexificação extremamente variável, ao nível de proposta, mas principalmente no nível de suas estruturações. Desta forma, o projeto ganha mais a conotação de intenção, um esboço de possibilidades, que vai sendo desvendado junto ao processo de composição, nas aberturas e nas necessidades que vão sendo instauradas. Trata-se de um encaminhamento no sentido "da ordem da percepção poética e não da dedução" (Zumthor apud Vittori, 2015, p. 13). É o artista que estabelece suas regras, na percepção e agenciamento das aberturas possíveis e dos caminhos trilhados. Cada investigação acaba por adquirir necessidades especificas que estão intrinsecamente ligadas às maneiras singulares de fazer do artista-investigador.

Compreende-se que as características apresentadas até então possuem um entendimento mais geral, que configuram uma tipologia base do que vem a ser uma investigação em arte fora das especificações de subáreas. Trata-se de uma metodologia que concerne à prática do próprio artista em seu processo de criação, não 
comporta um projeto rigidamente preestabelecido, encontra seus referenciais teóricos em processo, constitui-se por parâmetros variáveis e extremamente flexíveis, tanto a nível de proposta quanto de estruturação, e instaura-se em auto processo de composição.

Assumindo essa ideia base de investigação em artes, é possível traçar algumas especificações na área das Artes Cênicas, buscando comparar seus contrapontos com os aspectos que vem sendo firmados como gerais, mas, que parecem estar mais relacionados com as particularidades das Artes Visuais.

\section{Características especificas de uma investigação em Artes Cênicas}

As maneiras de abordar a dimensão teórica nas investigações em artes e as maneiras de trabalhar a construção e o conteúdo do material de conhecimento produzido por esses estudos dentro da academia, são aspectos que estão inter-relacionados com uma variação de posicionamento sobre a colocação do que é definido como objeto de estudo. Neste âmbito, pressupõe-se parâmetros metodológicos mais específicos das subáreas artísticas dentro de uma tipologia base de investigação em artes.

Embora a investigação em arte com ênfase nas Artes Visuais tenha como ponto de partida o processo de criação do artista, o objeto de estudo "precisa ser criado com o corpus da pesquisa e ser lançado como uma seta" (Rey, 1996, p. 90), é apresentado como algo decorrente do processo. Ele estaria mais relacionado a um estudo da obra em processo, ou então de um processo de criação que constrói ou encontra seu objeto de estudo. Rey (1996, p. 89) diz, por exemplo, que nas Artes Visuais o objeto de estudo é desenvolvido em conjunto com uma investigação teórico, onde o investigador "precisa produzir seu objeto de estudo para daí extrair as questões que investigará pelo viés da teoria".

Já em uma investigação em Artes Cênicas, o que se identifica é que o objeto de estudo não se configura como algo que diz respeito ao processo de criação, ele é o próprio processo de compor o processo. Como afirma Marta Isaacsson (2006, p. 85), "a compreensão da criação cênica qualificada como movimento de experimentações de 'possíveis', em busca de formas materiais e imateriais, autoriza a pensar que o processo criativo preserva intrinsecamente uma atitude investigatória".

O objeto de estudo passa a ser o próprio processo prático de estruturação da investigação em criação; a ação de estruturar o processo é ao mesmo tempo a própria investigação e objeto de estudo. Nesta abordagem metodológica eles se tornam uma mesma coisa: o próprio ato de constituir uma rede complexa que vai se desdobrando na descoberta de materiais, na articulação de conceitos, na integração de referências teóricas e poéticas, nas experimentações, experiências e agenciamentos de cada ator em seu processo investigativo. O agenciamento é empregado aqui do mesmo modo como Barros e Kastrup (2009, p. 57) o utilizam precisamente na cartográfica: "uma relação de cofuncionamento, descrita como um tipo de simpatia. A simpatia não é um mero sentimento de estima, mas uma composição de corpos envolvendo afecção mútua". Um gerenciamento no sentido de encaminhamento, onde o agenciador se encontra entranhado no processo. 
Há aqui uma diferença fundamental sobre o posicionamento do investigador perante as duas qualidades de objetos de estudo que são aqui apontadas. $O$ investigador em Artes Visuais percorre um processo de criação que se assume intuitivo, mas realiza um trabalho de investigação que está mais relacionado com aspectos que se direcionam à análise de seu processo, da obra, ou de algumas características deles - ou de um deles - que são eleitos e relacionados com aspectos da estética, da história da arte, ou de outros processos e obras. Mesmo que o investigador possa empregar uma "reflexividade própria" (Dias, 2015, p. 47), ele parece desempenhar enquanto investigador, uma ação mais voltada para a dissecação e comparação do seu trabalho prático. Já o investigador em Artes Cênicas, ao percorrer seu processo de criação, realiza a investigação totalmente implicado em um fazer do processo que articula constantemente intuição, experiência e análise, de maneiras imbricadas. Sua postura de investigação também possui aspectos de análise, mas estariam mais ligadas a uma compreensão da estruturação e de uma reflexão em processo e não apenas sobre ele. A questão fundamental é que a investigação em Artes Cênicas proposta aqui, não se assenta na análise, mas sim na compreensão enquanto mecanismo epistemológico de conhecimento, que incide sobre uma estrutura ampla e complexa de elementos que se articulam de forma imbricada.

Relacionando essa abordagem metodológica que funde objeto de estudo e investigador, é possível perceber uma colocação diferente no que diz respeito às configurações de aspectos práticos e teóricos em cada um dos dois modos de investigar que vem sendo colocados e discutindo.

Embora a investigação em Artes Visuais compreenda que o artista encontra as questões teóricas com o caminhar da exploração em processo prático, o estudo se faz de um conjunto prático-teórico das questões que emergem da prática para a teoria, e do que a teoria devolve para a prática, em um trânsito constante (Rey, 2002). Ou seja, a investigação teórica é desenvolvida em paralelo com a investigação prática, possuindo uma estreita relação de interdependência. Neste aspecto, mesmo partindo dela, a investigação de componente teórico não vem a se instaurar na prática, mas em relação a ela. Como afirma Mendes (2015, p. 73), "à dissertação ou apresentação que as acompanha compete fazer compreender a intencionalidade, a relevância e a inovação contidas na abordagem (conceptual, estética, tecnológica) praticada e sua eventual projeção futura". Há um enfoque na obra e/ou no processo de criação, como meio de articular um discurso, onde os conceitos são abordados como material de reflexão na prática, mas principalmente, sobre ela e/ou sobre a obra.

Desta forma, cabe dizer que o material de conhecimento produzido se estabelece como um texto teórico que reflete sobre um objeto de estudo. Seria um documento apresentado como um material derivado da pesquisa prática, que é construído de uma reflexão sobre o processo e que elucida a pesquisa no âmbito de sua conceitualização teórica, falando da obra em processo de construção, dos conceitos sobre o qual ela se construiu e dos conceitos que ela busca empregar. O material de conhecimento, neste caso, cumpre a função de representar uma investigação que igualmente se debruça em representar um objeto de estudo, pois mesmo que não inicie com um objeto predefinido, o determina em processo e desenvolve sua escrita em função deste. 
Já em uma investigação em Artes Cênicas o estudo flui eminentemente enquanto prática. Uma prática que engloba a práxis e a teoria, compreendendo que a pesquisa teórica nesse percurso de investigação é também prática, por se entrelaçar a práxis e por não se ater à articulação de conceitos, mas sim à assimilação e produção deles. O que se estabelece é a criação de um processo que se compõe imbricado de conexões entre materiais teóricos e outras diversas fontes, que ganham mais um aspecto de influência do que propriamente de referência, na medida em que influi (afeta), mais do que serve de modelo ou base. "Em seu percurso criativo, o artista se move por associações pessoais, revela sua apreensão da realidade, reage ao contato com diferentes elementos, movimentos que só podem ser identificados através de um olhar sensível" (Isaacsson, 2006, p. 82).

Neste aspecto, a teoria neste viés de investigação não é abordada como uma paralela que irá fundamentar o material de conhecimento produzido. Este material, por sua vez, não se constrói como reflexo de um estudo empreendido sobre um objeto, ele é também investigação e, portanto, também objeto a ser estudado. Não pretende representar conhecimento, mas sim, o gerar. Trata-se de um material que se configura não como algo que deriva do processo, mas como uma escritura em estruturação, junto à estruturação do processo. Um material construído na e pela investigação, experimentando e compondo modos de empreender, e também, de dizer e comunicar conhecimento, através de uma narrativa própria do investigador.

Em decorrência dessas reflexões apresentadas, há uma questão que pode ser levantada: se a investigação em Artes Cênicas se dá enquanto processo de criação artística na prática de investigação do ator, tendo um objeto de estudo que se configura como a própria ação de estruturar/acompanhar esse processo e desenvolve uma escrita que não visa representar um objeto, o que abordaria o material acadêmico de conhecimento teórico que ela constrói? O que viria a ser uma dissertação ou uma tese desenvolvida nesta proposta de investigação em Artes Cênicas?

Assimilando que esta proposta de estudo na área das Artes Cênicas pode ser entendida como uma possibilidade de caminho cartográfico, é possível se apropriar de algumas características do que vem a ser o método da cartografia, desenvolvendo e aprofundando as reflexões sobre os parâmetros de uma investigação em Artes Cênicas; para poder apresentar de maneira mais clara os aspectos e o conteúdo de uma escritura forjada neste meio de trabalho. Um material de conhecimento que dê a conhecer a investigação, permitindo aceder ao conhecimento que ela emprega e que por sua vez, produz.

\section{Por uma apropriação do método da cartografia}

A cartografia é um conceito que recentemente tem sido abordado no Brasil em algumas investigações acadêmicas, principalmente na área da psicologia, em pesquisas etnográficas e nas áreas artísticas. Segundo Kastrup, trata-se de um método formulado por Gilles Deleuze e Felix Guattari que visa acompanhar um processo, e não representar um objeto; "em linhas gerais, trata-se sempre de investigar um processo de produção" (Kastrup, 2009, p. 32). 
Atentos para a qualidade de um método que não possui maneiras pré-estabelecidas de fazer através de regras ou norma a serem seguidas, os autores do livro Pistas do método da cartografia: pesquisa-intervenção e produção de subjetividade (Passos; Kastrup; Escóssia, 2009), trazem oito pistas que dizem respeito ao método da cartografia. Estas servem como um referencial para a prática do cartógrafo: trata-se de um método de pesquisa-intervenção; diz respeito ao acompanhamento de processos e não a representação de objetos; requer um posicionamento especifico da atenção do cartógrafo ao presente; se apropria de dispositivos para se estabelecer; diz respeito ao agenciamento de um coletivo de forças; necessita de uma dissolução do ponto de vista do observador; pressupõe a habitação de um território existencial; e, necessita de novas práticas de narrar. Estas pistas apontam características de um método de investigação que, no lugar de enquadrar, propõe ampliar as possibilidades de caminhos do processo investigativo.

Tendo como interface o processo de criação do ator, a investigação em Artes Cênicas vem a se instalar como uma possibilidade de caminho onde o ator-investigador se faz cartógrafo de seu próprio processo de criação, se estabelecendo como um investigador-cartógrafo-criador. Neste aspecto, a investigação em Artes Cênicas já pressupõe e elucida as características de acompanhamento de processo, de pesquisa-intervenção e de habitação de um território existencial, que o método cartográfico apresenta. Acaba por se instaurar como um processo em estruturação a ser acompanhado, que existe apenas ao ser habitado/construído pelo próprio investigador. Mostra-se nítida "a inseparabilidade entre conhecer e fazer, entre pesquisar e intervir [...]" (2009a, p. 17), da qual falam Eduardo Passos e Regina Barros, a respeito do método cartográfico.

Compreendendo a possibilidade de atribuir à investigação em Artes Cênicas a qualidade de um caminho cartográfico, é possível situar as discussões aqui, sobre o entendimento de uma investigação-cartográfica-criativa. Essa tríade, seja na qualidade de verbo ou de substantivo, constitui um movimento de coexistência, de transversalidade, onde cada um se encontra imbricado no outro. Este caráter de transversalidade, como abordam Passos e Eirado (2009, p.115), se estabelece como uma

[...] alteração do padrão comunicacional nas instituições, defendendo um terceiro eixo que cruza e desestabiliza os eixos vertical e horizontal da comunicação nas instituições (eixo vertical da hierarquização da comunicação dos diferentes e o eixo horizontal que homogeneíza a comunicação na corporação dos iguais.

Trata-se de um eixo comunicacional que integra o processo de investigação, pois as relações de forças que o vão constituir existem como forças heterogêneas, mas que não possuem relações de hierarquia, pois elas irão justamente se estabelecer por um processo constitutivo de comunicações transversais.

A investigação em Artes Cênicas possui implicações de uma pesquisa-intervenção, ao estabelecer-se como uma metodologia constitutiva em um processo de caminhos que se desdobram em mais caminhos e assim se constrói. Passos e Barros (2009a, p. 17), afirmam, sobre o método cartográfico, que o que se pretende é instaurar uma "reversão do sentido tradicional de método - não mais um caminhar para 
alcançar metas prefixadas (metá-hódos), mas o primado do caminhar que traça, no percurso, suas metas. A reversão, então, afirma um hódos-metá" ${ }^{3}$. É neste aspecto que o projeto ganha a conotação de intenção e o processo se caracteriza como devir. O processo não se desenvolve a partir de uma diretriz estabelecida, nem mesmo tenciona estabelecê-la. Como afirma Ceres Vittori (2015, p. 71), sobre o método cartográfico, "[...] não há comprovações, mas questionamentos e suposições".

Na medida em que o objeto de estudo da investigação em Artes Cênicas se configura como a prática do "próprio processo de compor o processo", é possível dizer que esta investigação possui um coração cartográfico, pois segundo Barros e Kastrup (2009), o coração da cartografia está no entendimento de processo enquanto processualidade. A investigação, assim como a cartografia, não tem por finalidade abordar e representar um objeto, ela se ocupa de acompanhamento de processo. $O$ ponto aqui é que o que ocorre na investigação em Artes Cênicas é a fusão de processos, ou antes, uma investigação que se ocupa de várias camadas de processualidade. O debruçar-se sobre o próprio investigar da criação constitui um estudo que só existe nesse debruçar-se e que só compõe cartografia no ato de cartografar para constitui-lo. Se instaura uma dimensão que não dissocia "o ele, o nele e o por ele", do processo. O objeto de estudo, desta forma, é mais o agenciamento de um conjunto de forças ou antes, o próprio fluxo da investigação de compor esta investigação.

Este compor diz respeito ao fazer, habitar e agenciar um território existencial. Na cartografia, "a habitação de um território existencial está mais ligada a uma disposição de composição do que à execução de normas técnicas. Não se dirige a uma submissão ou um domínio do campo pesquisado, mas a um fazer com, compondo com os elementos envolvidos" (Alvarez; Passos, 2009, p. 148). Em relação a investigação em Artes Cênicas, não é possível uma dissociação entre o processo de criação e o território, pois estes existem como um processo-território habitado.

A experiência de habitar a investigação compõe um saber que se constrói no próprio ato de encarna-la, de se embrenhar neste processo-território em questão, de se lançar ao desconhecido para então conhecê-lo. Um fazer-saber e um saber-fazer que se dá no agenciamento de sua experiência. Um fazer que encontra potência no intuitivo. "A intuição mostra-se como via de acesso a um plano de transpasse, de transformação, de recombinação e de deslocamento" (Amador; Fonseca, 2009, p. 32). Ela seria uma potência de movimentação da investigação, para se percorrer a estruturação da investigação, articulando o que vai sendo cartografado e o que está a devir. Embora a investigação tenha uma potência intuitiva - é imprescindível um habitar sensível-intuitivo -, é na ação de agenciamento do plano de coletivo de forças de sua composição enquanto processo-território, que ela se estabelece.

Escóssia e Tedesco (2009) definem plano do coletivo de forças como uma área onde as próprias forças entram em relação, e assim se estabelece como um plano onde as regras não são fixas e não há tendência para determinar as relações, pois as composições tendem a se complexificar nas múltiplas direções de composição. Seria um plano que diz respeito às forças de composição das coisas para além de suas con-

3 Metá (reflexão, raciocínio, verdade) + hódos (caminho, direção) (Passos; Barros, 2009a, p. 17) 
figurações, podendo as desarranjar de seu funcionamento habitual para emprega-las sobre logicas próprias. A investigação assim, fugindo da representação da realidade das coisas, acessa o plano movente. Ela se constrói no próprio plano do coletivo de forças, nos agenciamentos dos materiais, linhas de forças e dispositivos que se fazem necessários para compor o processo. Dispositivos que, como abordam Kastrup e Barros (2009), desembaraçam as linhas que compõem o processo de criação e investigação, e se estabelecem enquanto práticas e funcionamentos que alteram de alguma forma o processo, pois geram algum efeito sobre ele. Seriam os modos de acessar, produzir, transformar e cartografar o plano coletivo de forças.

Sobre estes apontamentos, cabe dizer que o processo-território se estabelece em - e como - seu próprio plano de coletivo de forças e, portanto, é este o campo em que o investigador habita e atua. Estando o investigador a atuar no agenciamento de um processo complexo que se centra na instabilidade de compor um plano coletivo de forças e que tem como um de seus princípios a multiplicidade, é necessário que se estabeleça, como diz Kastrup (2009), uma atenção que não tencione simplesmente selecionar informações. Pois o que se pretende aqui não é sobretudo informar, mas sim construir - processo, território, realidade, subjetividade, conhecimento.

A partir dos estudos já realizados sobre a atenção, Kastrup (2009, p. 48) problematiza a do cartógrafo e fala do cultivo de uma que seria definida como uma constante procura por um "tônus atencional", que se encontra entre o "relaxamento passivo e a rigidez controlada". Seria uma espécie de atenção aberta à multiplicidade e à processualidade da investigação, que quando foca em algum elemento ou linha de força, o faz para que possa encontrar novos caminhos, estabelece momentos de zoom, para poder ampliar cada vez mais a abertura do plano. Amador e Fonseca (2009, p. 35) afirmam que "trata-se de uma atenção relacionada à consciência tomada enquanto domínio de mutações e aberta ao encontro; uma atenção que recusa a simples seleção de informações para detectar signos e forças circulantes, o que requer uma concentração sem focalização".

Desta forma, o investigador precisa estar aberto para encontrar e articular as linhas de força nas diversidades de materiais, linguagens, intensidades, acontecimentos ou elementos quaisquer que ele julgue possíveis e necessários, absorver e agenciar. Essa abertura ao encontro evidencia uma atitude antropofágica da qual fala Rolnik (2006, p. 65): “[...] o cartógrafo absorve matéria de qualquer procedência. Não tem o menor racismo de frequência, linguagem ou estilo". Ele se apropria de qualquer material que possa se estabelecer enquanto força de potência influidora a ser absorvida. "Tudo que der língua para os movimentos do desejo, tudo o que servir para cunhar matéria de expressão e criar sentido, para ele é bem-vindo" (Rolnik, 2006, p. 65). Os referenciais teóricos que a Investigação articula vem a se estabelecer igualmente sobre esse entendimento.

A prática do investigador-cartógrafo-criador não estaria ligada à busca pela definição das coisas, muito menos pela explicação do caminho do processo ou de suas forças. Como afirma Braga (2006), ao falar de sua atitude diante do processo de criação, a intenção seria mais a de conhece-lo do que explicá-lo. Trata-se de uma prática que diz mais respeito a um agenciamento que visa o princípio da multiplicida- 
de, da qual falam Deleuze e Guatarri (1995, p. 15), como sendo algo que "[...] não tem nem sujeito nem objeto, mas somente determinações, grandezas, dimensões que não podem crescer sem que mude de natureza (as leis de combinação crescem então com a multiplicidade)". O investigador se instaura como um complexificador, um agenciador que cria conexões ao mesmo tempo que as desestabiliza e as modifica, que amplia o plano coletivo de forças influindo sobre elas sem defini-las. Afinal, "um agenciamento é precisamente este crescimento das dimensões numa multiplicidade que muda necessariamente de natureza à medida que ela aumenta suas conexões" (Deleuze; Guattari, 1995, p. 16). Desta maneira, é nos agenciamentos que o investigador cartografa. É neles e através deles que se constrói uma cartografia.

Nessa proposta de trabalho, o cartografar que existe em uma transversalidade criadora e investigativa corresponde à prática de agenciar, mas também de mapear a processualidade, com o intuito de construir um material que articula o conhecimento do processo e, também, conhecimento através dele. Neste aspecto, as dissertações ou teses que viriam a ser desenvolvidas nesses estudos se configurariam como uma espécie de cartografia do processo, que é empregada como um desenho que não é estático, que não foi configurado como representação de uma forma. Como traz Suely Rolnik (2006, p. 23), "para os geógrafos, a cartografia - diferente do mapa: representação de um todo estático - é um desenho que acompanha e se faz ao mesmo tempo que os movimentos de transformação da paisagem". Já Deleuze e Guattarri (1995, p. 21) falam de cartografia como um mapa, mas um mapa que é o oposto de decalque: "se o mapa se opõe ao decalque é por estar inteiramente voltado para uma experimentação ancorada no real. O mapa não reproduz um inconsciente fechado sobre ele mesmo, ele o constrói". O importante é a compreensão de que compor essa cartografia constrói realidade ao mesmo tempo que a modifica. Ela mesma se instaura enquanto desenho autônomo, não se constituindo sobre a representação do processo, mas no processo. Sua composição se faz uma das linhas de força.

É possível identificar que nesta investigação que tem sido apresentada e discutida até aqui, a cartografia, enquanto mapeamento do processo, acaba por ser composta em pelo menos duas dimensões. A primeira seria uma cartografia-cênica, que diz respeito à construção do material de cena a ser apresentado enquanto obra; e a segunda, a composição de uma cartografia-mapa que se estabelece como uma documentação produzida do - e no - rastreamento, registro e transfigurações dos vários aspectos que a investigação comporta.

A dimensão relativa à cartografia-cênica diz respeito à estrutura cênica que vai sendo construída para ser compartilhada com o público enquanto obra. Essa estrutura também se faz cartografia: um desenho cênico que vai se construindo nos movimentos de conexões que são feitos e que não se estruturam como formas fixas, isto quer no que diz respeito a uma estrutura de ações, tensões, movimentos, forças e (ou) potências que o ator irá desenhar a cada apresentação; quer sobre a estrutura de espaço que também não se comportaria como uma forma estática, mas como uma organização que mantem seu movimento de mutação. Embora tenha sido utilizado o termo obra para se referir a essa dimensão cartográfica, o entendimento que se tem aqui não diz respeito à obra enquanto estrutura final, mas como uma estrutura que 
será sempre um desenho em fluxo. Não se configurando como um ato de representar uma estrutura cênica que se estabeleceu, mas como o próprio desenho que se constrói enquanto movimento efêmero de presentificação no tempo-espaço, feito do contato com o público, no momento de apresentação. Uma cartografia-cênica, presentificação, e não decalque, representação.

A dimensão relativa à cartografia-mapa, diz respeito à construção de um documento de conhecimento que se apresenta não apenas como uma espécie de registro da investigação em seus vários aspectos de estruturação e composição, mas como um desdobramento do processo, uma transfiguração deste em uma outra linguagem. Registro, menos como a inscrição de um facto e mais no aspecto de pegadas, migalhas, rastros de um processo que são tomados como elucidação de um conhecimento que se estabelece no fazer. Um documento, não como uma documentação do processo, mas como material que é construído em processo e que se faz rascunho de um processo escritura que existe como rastro, e sobre os rastros da investigação. Um material construído "[...] para testemunhar e conversar. Não para conservar..." (Braga, 2006, p. 81). Trata-se de uma escritura que para além de elucidar um conhecimento empírico, também o produz, na medida em que estrutura um material que busca partilhá-lo.

As duas dimensões da cartografia na investigação em Artes Cênicas se estabelecem como material de conhecimento que ela vem a construir como investigação acadêmica. A primeira proporciona ao público o acesso a um conhecimento vivo da experiencia dos aspectos poéticos, artísticos e estéticos, que se estabelecem ao vivenciar o material cênico. Já a segunda, traz um material que elucida o conhecimento do fazer e sobre o fazer, dando a ver o próprio processo. Além disso, a segunda proporciona também a experiência de apreensão de uma escritura particular do investigador, que acaba imprimindo os mesmos aspectos poéticos, artísticos e estéticos que se instauram na cena e no processo, sobre esta outra linguagem.

Estes pressupostos suscitam uma articulação subjetiva dos modos de dizer, de comunicar conhecimento. $O$ investigador trabalha na construção de materiais de conhecimento que se estabelecem com uma natureza narrativa particular. Passos e Barros (2009b, p. 150) falam de uma política da narratividade, sobre uma posição narrativa que seria o ethos da investigação e afirmam que "toda a produção de conhecimento, precisamos dizer de saída, se dá a partir de uma tomada de posição que nos implica politicamente". O conceito de política que eles empregam diz respeito a um sentido ampliado de política como uma " [...] forma de atividade humana que, ligada ao poder, coloca em relação sujeitos, articulando-os segundo regras e normas não necessariamente jurídicas e legais " (2009b, p. 151). Trata-se de uma configuração de poder que pode se instituir em escalas menores, em arranjos locais.

Neste sentido, podemos pensar a política da narratividade como uma posição que tomamos quando, em relação ao mundo e a si mesmo, definimos uma forma de expressão do que se passa, do que acontece. Sendo assim, o conhecimento que exprimimos acerca de nós mesmos e do mundo não é apenas um problema teórico, mas um problema político. (Passos; Barros, 2009b, p. 151) 
Esta política de narratividade não diz respeito apenas a um determinado posicionamento narrativo em aspectos da composição escrita do documento de conhecimento a ser construído, ela também está implícita nos aspectos que abrangem todo o processo investigativo, na medida em que agenciar implica em estabelecer uma posição narrativa sensível, que se estabelece em transversalidade objetiva e subjetiva e que, como o processo, é constitutiva. Imbricada com este posicionamento, a narrativa enquanto maneira de dizer e construir um material de conhecimento é encarada como uma proposta que estabelece a articulação do formato de documento de conhecimento acadêmico que seja aberto ao entendimento deste material também enquanto uma construção subjetiva e ainda, de subjetividade. Um material que tem uma estrutura organizacional variável, que necessita fazer uso de uma escrita em primeira pessoa e que pode vir a incorporar outras linguagens que não só a do texto e da imagem - habitualmente utilizadas.

Ceres Vittori, por exemplo, que trabalha com o conceito de cartografia, em sua tese de doutoramento em Letras: Pistas, rizomas, devires: por uma cartografia da peça radiofônica "para acabar de vez com o julgamento de Deus" (2015), fala sobre - e também emprega - uma "bivocalidade" que articula uma voz acadêmica analítica e uma voz subjetiva, onde estas não necessitam estabelecer obrigatoriamente uma coesão textual, e cuja segunda voz mencionada diz respeito aos registros em um diário de bordo que são trazidos em itálico no corpo do texto, que é nomeado por ela de escritura. Trata-se de fragmentos poéticos e em primeira pessoa, que são articulados em sua escritura. Vittori traz a compreensão de uma voz processual que apreende a teoria-critica no processo de cartografar, enquanto a voz acadêmica a utilizaria como principal fio condutor.

Sobre este entendimento, a política de narrativa da cartografia-mapa na investigação que é proposta aqui, não exclui o caráter teórico-crítico do conhecimento, ela na verdade é muito mais acolhedora do que excludente. A questão é que a articulação crítica não é feita sobre o processo, mas, com ele; abordando o caráter reflexivo para, com e de sua composição. Não se trata apenas de um conhecimento teórico-crítico e sim de algo que se estabelece dando a ver o próprio processo, na medida em que diz respeito a um conhecimento próprio do fazer e de suas potências reflexivas. Desta forma, a cartografia-mapa abordada aqui, é articulada por uma espécie de voz processual subjetiva do artista que traz seu processo de composição e sua composição, abrindo possibilidades de uma reflexão particular sobre a investigação, por parte de quem a apreende - construindo assim, também subjetividade.

Por exemplo, Raquel Scotti Hirson, em sua dissertação de mestrado Tal Qual Apanhei do Pé (2003), apresenta um relato reflexivo de suas experiências no processo coletivo de criação do espetáculo Taucoauaa Panhé Mondo Pé em 1993, em seu primeiro ano de investigação como atriz do grupo LUME - Núcleo Interdisciplinar de Pesquisas Teatrais da Universidade Estadual de Campinas. Hirson, na verdade, narra também seu percurso na graduação em Artes Cênicas que a levou ao referente processo. Ela compõe em sua escrita a narrativa de seu caminho de investigação e suas reflexões, articulando uma voz que traz suas vontades, inquietações, percalços, duvidas, escolhas. Ela constrói uma reflexão crítica entranhada na narrativa do seu processo, permitindo que o leitor reflita sobre o processo e sobre suas reflexões. 
Já Ana Cristina Colla, em sua tese de doutoramento em Artes Caminhante, não há caminho. Só rastros. (2010), traz um texto que se compõe exclusivamente de uma narrativa, em primeira pessoa, de seu processo de investigação na criação de seu espetáculo solo, Você. Dando a ver o conhecimento do fazer em artes cênicas, de sua poética cênica pessoal de criação e os rastros do caminho de seu fazer, ela compõe sua escritura com datas, trechos mais poéticos, outros mais descritivos, desenhos, músicas, fotografias, transcrições diretas de diálogos e até, por vezes, propõe criar um diálogo direto com leitor - que se torna interlocutor - trazendo sugestões para abordagem da leitura. Este trabalho de Colla é um exemplo preciso de investigação em Artes Cênicas que elucida seu caráter enquanto investigação-cartográfica-criativa, no qual sua tese, que se comporta como uma espécie de cartografia do processo, condiz com os aspectos processuais e com a poética trazida pela atriz em seu estudo, ao qual o próprio material permite aceder.

Decorrente das reflexões aqui desenvolvidas, que apresentam a investigação e a cartografia como uma composição complexa de forças, onde se entende que "o cartógrafo é um verdadeiro antropófago: vive de expropriar, se apropriar, devorar e desovar, transvalorado" (Rolnik, 2006, p. 65) sobre materiais e linguagens, é imprescindivel compreender que a expressão textual é uma das muitas linguagem que ele pode articular para cartografar seu processo e compor sua cartografia-mapa. Entende-se que as composições do documento que a investigação constrói e apresenta como material de conhecimento a ser partilhado - seja nas maneiras de narrar, de compor este documento (práticas cartográficas), bem como as suas possibilidades de estruturar sua materialidade (texto, desenho, foto, áudio, vídeo, e etc.) - são extremamente variáveis e constitutivas, assim como os processos nos quais elas estão imersas e dizem respeito.

\section{Considerações Finais}

O que se apresenta aqui é uma reflexão acerca de uma das possíveis abordagens que podem ser assumidas para a investigação artística em Artes Cênicas dentro da academia. Uma possibilidade de caminho que se instaura na ideia de estruturação, e não de estrutura, construindo-se pelo próprio meio que abarca, em articulações transversais. Nesta vertente, pesquisa, processo, território, cartografia e criação, são termos que designam forças de processualidade heterogênias que existem em transversalidade nessa investigação, que aqui é identificada como um caminho cartográfico possível.

Trata-se de uma metodologia que, ao ter como interface o processo de criação artístico, não diz respeito ao trabalho de criação de uma obra enquanto objeto material perdurante, mas de uma obra-processo que estabelece pontos de conexões das forças agenciadas em investigação, instituindo cartografias no âmbito da composição de materiais artísticos (cenas, performances, espetáculos) e de documentos de conhecimento acadêmico (artigos, dissertações, teses). Funcionando em conjunto, essas dimensões cartográficas, no lugar de explicar, exprimem um processo artístico de criação e o dão a ver como conhecimento artístico-acadêmico. 
É o entendimento de que a criação em Artes Cênicas se desapropria do caráter representativo - que por muito tempo foi empregado a ela - para se apropriar de seus aspectos processuais e performáticos, que torna possível abordá-la como material de conhecimento em artes e articulá-la como uma investigação-cartográfica-criativa que se estabelece enquanto um processo-território potente de experimentações e possibilidades, não compondo início ou fim, apenas meio, caminho.

\section{Referências}

ALVAREZ, J.; PASSOS, E. Cartografar é habitar um território existencial. In: PASSO, E.; KASTRUP, V.; ESCÓSSIA, L. da (Orgs.). Pista do método da cartografia: pesquis-intervenção e produção de subjetividade. Porto Alegre: Editora Sulina, 2009, p. 131-149.

AMADOR, F.; FONSECA, T. M. G. da intuição como método filosófico à cartografia como método de pesquisa: considerações sobre o exercício cognitivo do cartógrafo. Arquivos Brasileiros de Psicologia, Rio de Janeiro, v. 61, n. 1, 2009, p. 30-37.

BARROS, L. P. de; KASTRUP, V. Cartografar é acompanhar processos. In: PASSO, E.; KASTRUP, V.; ESCÓSSIA, L. da (Orgs.). Pista do método da cartografia: pesquis-intervenção e produção de subjetividade. Porto Alegre: Editora Sulina, 2009, p. 52-75.

BRAGA, B. Raspas e restos me interessam. In: CARREIRA, A. et al. (Orgs.). Metodologias de Pesquisa em Artes Cênicas. Rio de Janeiro: 7 Letras, 2006, p. 78-81.

BRANTES, H. R. S. Busca por uma metodologia de pesquisa em poéticas visuais. 2013. Anais do VI Seminário Nacional de Pesquisa em Arte e Cultura Visual, Goiânia, p. 602-611.

COLLA, A. C. Caminhante, não ha caminho. Só rastros. Campinas, 2010. Tese (doutorado) - Instituto de Artes, Universidade Estadual de Campinas.

DELEUZE, G.; GUATTARI, F. Mil platôs: capitalismo e esquisofrenia. vol. 1. Tradução: Aurélio Guerra Neto; Célia Pinto Costa. 1. ed. Rio de Janeiro: Editora 34, 1995.

DELEUZE, G.; GUATTARI, F. Mil platôs: capitalismo e esquizofrenia vol. 4. Tradução: Suely Rolnik. 1. ed. São Paulo: Editora 34, 1997.

DIAS, F. R. Tempos da Investigação em Artes - caminhar no método entre a dúvida, a crítica e a ironia. In: QUARESMA, J.; LONGLEY, A.; DIAS, F. R. (Orgs.). Investigação em Artes: Ironia, Crítica e Assimilação dos Métodos. Lisboa: inPrintout, 2015, p. 44-58.

ESCÓSSIA, L. DA; TEDESCO, S. O coletivo de forças como plano de experiência cartográfica. In: PASSO, E.; KASTRUP, V.; ESCÓSSIA, L. da (Orgs.). Pista do método da cartografia: pesquis-intervenção e produção de subjetividade. Porto Alegre: Editora Sulina, 2009. p. 92-108. 
FERREIRA, H. "Expor" ou perecer na investigação artística. In: QUARESMA, J.; LONGLEY, A.; DIAS, F. R. (Orgs.). Investigação em Artes: Ironia, Crítica e Assimilação dos Métodos. Lisboa: inPrintout, 2015, p. 112-119.

HANSSON, S. O. Science and Pseudo-Science. Stanford Encyclopedia of Philosophy, EUA, set. 2008. Disponível em: https://plato.stanford.edu/entries/pseudo-science/. Acesso em: 26 jan. 2017.

HIRSON, R. S. Tal qual apanhei do pé. Campinas, 2003. Dissertação (mestrado) - Instituto de Artes, Universidade Estadual de Campinas.

ISAACSSON, M. O desafio de pesquisar o processo criador do ator. In: CARREIRA, A. et al. (Orgs.). Metodologias de Pesquisa em Artes Cênicas. Rio de Janeiro: 7 Letras, 2006, p. 82-88.

JUNIOR, M. R.; BONFITTO, M. A "escrita dos erros": sobre os possíveis modos de registro na pesquisa em artes cênicas. Lamparina: Revista de Ensino de Artes Cênicas, v. 2, n. 7, p. 111-118, 2016.

KASTRUP, V. O funcionamento da atenção no trabalho do cartógrafo. In: PASSO, E.; KASTRUP, V.; ESCÓSSIA, L. da (Orgs.). Pista do método da cartografia: pesquis-intervenção e produção de subjetividade. Porto Alegre: Editora Sulina, 2009, p. 32-51.

KASTRUP, V.; BARROS, R. B. de. Movimentos-funções do dispositivo na prática da cartografia. In: PASSO, E.; KASTRUP, V.; ESCÓSSIA, L. da (Orgs.). Pista do método da cartografia: pesquis-intervenção e produção de subjetividade. Porto Alegre: Editora Sulina, 2009, p. 76-91.

MENDES, J. M. Da logofilia \& da logofobia na Arts-Based Research. In: QUARESMA, J.; LONGLEY, A.; DIAS, F. R. (Orgs.). Investigação em Artes: Ironia, Crítica e Assimilação dos Métodos. Lisboa: inPrintout, 2015, p. 70-88.

PASSERON, R. A poiética em questão. Porto Arte, v. 1, n. 21, p. 9-15, 2004.

PASSOS, E.; BARROS, R. B. de. A cartografia como método de pesquisa-intervenção. In: PASSO, E.; KASTRUP, V.; ESCÓSSIA, L. da (Orgs.). Pista do método da cartografia: pesquis-intervenção e produção de subjetividade. Porto Alegre: Editora Sulina, 2009a, p. 17-31.

PASSOS, E.; BARROS, R. B. de. Por uma politica da narratividade. In: PASSO, E.; KASTRUP, V.; ESCÓSSIA, L. da (Orgs.). Pista do método da cartografia: pesquis-intervenção e produção de subjetividade. Porto Alegre: Editora Sulina, 2009b, p. 150-171. 
PASSOS, E.; EIRADO, A. do. Cartografia como dissolução do ponto de vista do observador. In: PASSO, E.; KASTRUP, V.; ESCÓSSIA, L. da (Orgs.). Pista do método da cartografia: pesquis-intervenção e produção de subjetividade. Porto Alegre: Editora Sulina, 2009, p. 109-130.

PASSOS, E.; KASTRUP, V.; ESCÓSSIA, L. da (Orgs.). Pistas do método da cartografia: pesquisa-intervenção e produção de subjetividade. Porto Alegre: Editora Sulina, 2009.

REY, S. Da prática à teoria: três instâncias metodológicas sobre a pesquisa em poéticas visuais. Porto Arte, v. 7, n. 13, p. 81-95, nov. 1996.

REY, S. Por uma abordagem metodológica da pesquisa em artes visuais. In: BRITES, B.; TESSLER, E. (Orgs.). O meio como ponto zero: metodologia da pesquisa em Artes Plásticas. 1. ed. Porto Alegre: Editora da Universidade UFRGS, 2002, p. 125-140.

ROLNIK, S. Cartografia sentimental: transformações contemporâneas do desejo. 2. ed. Porto Alegre: Editora Sulina, 2006.

SANTOS, B. de S. Um Discurso Sobre as Ciências. 5. ed. São Paulo: Cortez, 2008.

SLAGER, H. Estética Experimental. In: QUARESMA, J.; LONGLEY, A.; DIAS, F. R. (Orgs.). Investigação em Artes: Ironia, Crítica e Assimilação dos Métodos. Lisboa: inPrintout, 2015, p. 60-69.

VINE, T. M. M. Dança vocal : a voz do movimento, o movimento da voz. Campinas, 2005. Dissertação (mestrado) - Instituto de Artes, Universidade Estadual de Campinas.

VITTORI, C. S. Pistas, rizomas, devires: por uma cartografia da peça radiofônica "para acabar de vez com o julgamento de Deus". Londrina, 2015. Tese (Doutorado) - Centro de Letras e Ciências Humanas, Universidade Estadual de Londrina.

ZAMBONI, S. A pesquisa em arte: um paralelo entre arte e ciência. 2. ed. Campinas: Autores Associados, 2001.

Recebido em: 01/07/2018 Aprovado em: 13/11/2018 